\title{
Upaya Integrasi Penanganan Nyeri Haid dengan Abdominal Stretching pada Remaja Puteri di Pesantren Baitul Ulum El-Musawwa, Serang, Banten
}

\author{
Desmawati \\ Maternity Nursing Department, Faculty of Health Science, \\ Universitas Pembangunan Nasioanal Veteran Jakarta \\ Email:desmawati@upnvj.ac.id
}

Published: 28/06/2021

\begin{abstract}
Menstrual pain or dysmenorrhea is a problem that is often faced by teenagers during menstruation. Dysmenorrhea occurs due to an imbalance of the hormone progesterone which causes uterine contractions and stimulate the pain response of each individual. Based on the underlying pathophysiology, there are two types of dysmenorrhea, namely primary dysmenorrhea and secondary dysmenorrhea, primary dysmenorrhea occurs in women of childbearing age in the form of pain in the lower abdomen so that it can disrupt their quality of life. Dysmenorrhea often interferes with teenagers' productivity and influences coping abilities. The purpose was to evaluate the abdominal stretching on the intensity of menstrual pain (dysmenorrhea) in teenagers. This public service is a test pretest of pain menstrual by using Visual Analogue Scale, demonstration-re-demonstration abdominal stretching, and evaluate pain scale of dysmenorrhea. From 26 participants founding that the level of menstrual pain at middle is $69.23 \%$, lower is $30.77 \%$, there are no severe pain levels. After abdominal stretching reduce the pain become $100 \%$ at lower pain and there are no moderate and severe pain levels. The Abdominal stretching exercise is recommended to be another alternative for reducing dysmenorrhea in teenagers that is easy, economic, safe and without side effects.
\end{abstract}

Keywords: abdominal stretching, dysmenorrhea, teenagers

\begin{abstract}
Abstrak
Nyeri haid atau dismenore merupakan masalah yang sering dihadapi remaja saat haid. Dismenore terjadi akibat ketidakseimbangan hormon progesteron yang menyebabkan kontraksi rahim dan merangsang respon nyeri masing-masing individu. Berdasarkan patofisiologi yang mendasari, terdapat dua jenis dismenorea yaitu dismenorea primer dan dismenorea sekunder, dismenorea primer terjadi pada wanita usia subur berupa nyeri pada perut bagian bawah sehingga dapat mengganggu kualitas hidup. Dismenore sering mengganggu produktivitas remaja dan mempengaruhi kemampuan koping. Tujuannya adalah untuk mengevaluasi intensitas nyeri haid (dismenore) pada remaja tentang peregangan perut (abdominal stretching). Pelayanan masyarakat ini merupakan penilaian skala nyeri melalui pretest posttest dengan menggunakan Visual Analogue Scale (VAS), demonstrasi-redemontrasi abdominal stretching, serta evaluasi skala nyeri dismenore. Dari 26 participants didapatkan hasil pre-test tingkat nyeri haid sedang $69.23 \%$, ringan $30.77 \%$, tidak ada kadar nyeri berat. Setelah abdominal stretching atau post test didapatkan; nyeri berkurang menjadi $100 \%$ pada nyeri ringan dan tidak ada nyeri tingkat sedang dan berat. Latihan peregangan perut disarankan menjadi alternatif lain untuk mengurangi dismenore pada remaja puteri, karena mudah dilakukan, murah, aman dan tanpa efek samping.
\end{abstract}

Kata Kunci: abdominal stretching, dysmenorrhea, remaja 


\section{PENDAHULUAN}

Masa remaja merupakan masa transisi dari anak-anak hingga dewasa pada masa ini merupakan periode remaja akan mengalami perkembang, remaja akan mengalami perubahan pada fisik dan seksual serta remaja akan membangun identitas diri mereka. (Batubara,2017). Usia remaja menurut Kemenkes Republik Indonesia adalah usia 10-18 tahun dan menurut WHO adalah 10-19 tahun.Pada anak perempuan pubertas terjadi pada usia 8 tahun dan laki-laki lebih lambat yaitu 9 tahun ${ }^{1}$. Menarche dialami oleh setiap remaja perempuan yang merupakan menstruasi pertama yang dirasakan pada pertengahan masa pubertas. Menurut hasil SDKI 2012 bahwa usia $89 \%$ remaja berusia 12-15 tahun sudah mengalami menarche.

Menstruasi merupakan salah satu tanda seksual yang telah matang yang terjadi pada masa pubertas seorang wanita ${ }^{2}$. Lama menstruasi alah 3-8 hari dengan siklus rata-rata normal 28 hari serta batas maksimal menstruasi dapat dikatakan normal adalah 15 hari $^{3}$. Salah satu keluhan yang dirasakan remaja pada masa menstruasi adalah nyeri haid (dismenorea). Dysmenorrhea merupakan keluhan yang terjadi karena adanya ketidakseimbangan hormon pada aliran darah yang menyebabkan timbulnya respon nyeri pada tubuh terutama pada perut bagian bawah ${ }^{4}$. Pada penelitian ${ }^{5}$, dari studi pendahuluan sebanyak 15 responden menangani nyeri tersebut dengan beberapa cara diantaranya, minum obat pereda nyeri sebanyak 5 orang (42\%), tidur sebanyak 2 orang (17\%), mengoles minyak kayu putih sebanyak 1 orang $(8 \%)$, minum air putih sebanyak 1 orang $(8 \%)$, dan tidak melakukan apa - apa sebanyak 3 orang (25\%). Menurut data WHO (2010), didapatkan kejadian sebesar 1.769.425 jiwa (90\%) wanita yang mengalami dismenorea dimana $10-15 \%$ termasuk ke dalam kategori dismenorea berat (Sabilu, 2017). Hal ini didukung dengan penelitian Gebeyehu, 2017, dalam terjemahan bebas menjelaskan bahwa sebanyak 90\% remaja dan lebih dari 50\% wanita yang sudah menstruasi di seluruh dunia pernah menderita dismenorea, dengan 10 - 20\% dari mereka menggambarkan nyeri mereka sebagai parah dan menyusahkan. angka dismenorea di Indonesia sekitar $55 \%$ perempuan dengan usia produktif yang mengalami nyeri selama masa menstruasi (Marlinda, 2013). Angka kejadian (prevalensi) nyeri menstruasi berkisar $45-95 \%$ di kalangan wanita usia produktif dimana sebanyak $54,89 \%$ mengalami dismenorea primer dan $9,36 \%$ mengalami dismenorea sekunder ( Windastiwi, 2017).

Penanganan nyeri dapat dibagi atas dua kategori yaitu secara farmakologi atau non-farmakologi. Secara nonfarmakologi dapat dilakukan kompres hangat, teknik relaksasi nafas dalam, yoga, akupresur, teknik imagenary, aromaterapi, dan teknik distraksi ( Sastra, 2018). Selain itu dengan berolahraga akan mampu meningkatkan produksi endorphin yaitu sebagai penenang dan pembunuh rasa sakit alami dalam tubuh, serta meningkatkan kadar serotonin ${ }^{5}$. Peregangan otot yang disarankan adalah peregangan otot pada perut dan panggul. Dengan melakukan peregangan otot diharapkan otot-otot akan melemas dan rileks, maka nyeri akan berkurang Rahmawati, 2017). Latihan fisik (exercise) sangat dianjurkan untuk mengatasi dismenorhea dan exercise menggunakan proses fisiologis tubuh sehingga aman dilakukan dan tidak ada efek samping yang ditimbulkan. Pada latihan fisik, tubuh akan menghasilkan endorfin yang berfungsi sebagai obat pembunuh rasa sakit alami yang diproduksi otak sehingga 
menimbulkan rasa tenang dan nyaman (Kemalaningtyas, 2016). Latihan fisik ini dirancang khusus untuk meningkatkan kekuatan otot daya tahan, dan fleksibilitas, sehingga diharapkan dapat mengurangi nyeri haid, meningkatkan kebugaran, mengoptimalkan daya tangkap, dan mengurangi nyeri otot pada masa menstruasi ( Ningsih, 2018).

Pondok pesantren AlMusawwa Serang Banten merupakan pesantren dengan anak santrinya mulai dari tingkat SMP dan SMA. Pada usia SMP dan SMA adalah usia remaji yang sering mereka rasakan adalah nyeri haid. Setiap menstruasi kerap mereka tidak bisa masuk kelas bagi yang biasa nyeri haid. Terlacak ada 16 orang yang nyeri haid.

\section{TARGET DAN LAUARAN}

Setelah edukasi abdominal stretching dapat menurunkan intensitas nyeri haid pada remaja puteri di pesantern Al Musawwa

\section{METODE PELAKSANAAN}

Pengabdian masyarakat ini dilakukan dengan metode sebagai berikut; rancangan pengabdian masyarakat; (2) Sasaran pengabdian masyarakat adalah santri pondok pesantren AlMusawwa sebanyak 26 orang yang dismenorrhe; (3) teknik pengumpulan data dengan pendidikan kesehatan (pre-post), demonstrating abdominal stretching dan pengembangan instrumen dengan menggunakan VAS pain scale yang sudah standard International, dan kuesioner tentang pengetahuan pre dan post, (4) dan teknik analisis data dengan manual dan analisis hasil observasi.

Alat dan media yang perlu adalah matras untuk senam, audio vicual untuk menayangkan video abdominal stretching, vitamin atau obat analgesic jika ada yang terlalu sakit saat perlakuan.

\section{HASIL DAN PEMBAHASAN}

Hasil keadaan nyeri haid remaja puteri setelah diberikan edukasi dan demonstrasi abdominal stretching seperti berikut;

\section{Gambaran data demografi remaja di Pesantren AlMusawwa Serang}

Tabel 1. Frekuensi dan persentase serta rata-rata data demografi remaji di Serang Banten $(n=16)$

Data demografi $\mathrm{n} \quad \%$

\section{Level pendidikan}

\begin{tabular}{lll}
-SMP & 11 & 68.75 \\
-SMA & 5 & 31.25 \\
\hline
\end{tabular}

Tampak pada table bahwa remaja putri yang SMP (berusia 12-15 tahun) ada $69 \%$. Usia 12,83 tahun atau 13 tahun merupakan subfase usia remaja awal, pada penelitian sebelumnya bahwa sebanyak 43,2\% responden berusia 13 tahun, hal ini dikarenakan usia tersebut remaja telah mengalami pubertas dan telah mengalami menstruasi sehingga dalam rentang 6 bulan atau sampai 1 tahun setelah menarche, dismenorea dapat terjadi dan pada saat ini kecenderungan anak mendapat menstruasi di usia yang lebih muda antara 8-12 tahun (Batubara, 2017). Hal tersebut dapat terjadi karena berbagai faktor seperti faktor kejiwaan atau emosi yang tidak stabil, usia pertama haid yang terlalu dini, lama menstruasi yang dialami, dan faktor lainnya.

Pada teori menjelaskan bahwa setiap manusia memiliki respon atau sensasi berbeda dan dapat dihubungkan dengan suku dan kultur mereka berasal, karena kultur akan mengajarkan bagaimana orang tersebut dalam merespon nyer (Batubara, 2017). Pengabdi belum dapat berasumsi bahwa teori tersebut dapat sejalan atau tidak dengan hasil ini apabila dilihat dari lokasi penelitian dengan penyebaran suku terbanyak adalah Sunda

Hasil SDKI 2012 menyatakan bahwa 23\% perempuan dengan 12 tahun dan $7 \%$ usia 10 sampai 11 tahun sudah mengalami menarche dan $89 \%$ usia menarche remaja di Indonesia dalam 
rentang usia 12-15 tahun. Usia menarche yang cepat adalah kurang dari 12 tahun, ini dikarenakan pada usia tersebut organ reproduksi remaja belum matang dan fungsinya belum sempurna sehingga belum siap dalam menghadapi perubahan biologis, seperti nyeri saat menstruasi.

\section{Level nyeri haid sebelum dan sesudah} melakukan abdominal stretching $(n=16)$

Tabel 2. Level nyeri haid

\begin{tabular}{lllll}
\hline Pain level & \multicolumn{2}{l}{ Pre test } & \multicolumn{2}{c}{ Post test } \\
\cline { 2 - 5 } & $\mathrm{n}$ & $\%$ & $\mathrm{n}$ & $\%$ \\
Ringan & 8 & 30.77 & 26 & 100 \\
Sedang & 18 & 69.23 & 0 & \\
Berat & 0 & 0 & 0 & \\
\hline
\end{tabular}

Tabel 2 diatas menunjukkan bahwa sebelum dilakukan intervensi remaja putri ada pada level nyeri sedang $(69.2 \%)$, namun setelah diberikan abdominal stretching, nyeri sedang berubah menjadi ringan $(100 \%)$. Selain intervensi abdominal stretching, ada factor lain yang mempengaruhi pengurangan nyeri haid yaitu; lama menstruasi yang normal dialami adalah 3-8 hari dengan siklus menstruasi 28 hari. Menurut Sabilu, semakin lama menstruasi yang dialami 2017, maka uterus akan terus berkontraksi sehingga semakin banyak hormon prostaglandin yang dikeluarkan dan hal tersebut dapat menimbulkan rasa nyeri. Pada penelitian sebelumnya terdapat kontribusi keletihan pada remaja yang mengalami nyeri haid dan teori menyebutkan bahwa rasa letih atau lelah sesorang membuat kopingnya menurun dan sensasi nyeri yang di rasakan jauh lebih intensif (Sabilu, 2017).

Dismenorea yang dirasakan oleh remaja salah satunya dapat dikarenakan oleh faktor biologis tubuhnya. Penyebab dismenorea primer adalah adanya prostaglandin yang menstrimulasi kontraksi uterus yang di hasilkan oleh endometrium ${ }^{1}$. Akibat adanya kontraksi uterus, menghasilkan prostagladin dan mengakibatkan vasopasme arteriol uterus, yang jika terjadi secara terus menerus akan meningkatkan amplitude dan frekunsi kontraksi di uterus, sehingga menimbulkan kram didaerah bawah perut dan mengakibatkan iskemik hingga dirasakan adanya sensasi nyeri.

Namun tampak abdominal stretching atau latihan peregangan otot sendiri pun bertujuan untuk membantu meningkatkan oksigenisasi dan proses pertukaran oksigen di dalam sel sehingga dapat meningkatkan elatisitas dan fleksibilitas tubuh dan mengurangi kram otot (Ningsih, 2018). Pengaruh abdominal stretching dan musik klasik terhadap intensitas nyeri haid pada remaja puteri menunjukkan bahwa remaja puteri rata-rata mengalami nyeri haid sedang sebelum dilakukan intervensi dan setelah dilakukan intervensi terjadi penurunan pada remaja dan rata-rata mengalami nyeri haid ringan, Hal ini disebabkan karena latihan Abdominal stretching sama dengan senam/olahraga, pada saat senam/berolahraga, tubuh akan mengeluarkan hormon endorphin yang akan ditangkap oleh hipotalamus yang berfungsi mengatur emosi seseorang. Kadar endorphin setiap individu berbeda-beda dan hal tersebut dikarenakan oleh beberapa faktor, individu dengan endorphin yang banyak akan lebih sedikit merasakan nyeri ( Chan, 2019).. Setelah melakukan latihan abdominal stretching, responden menyatakan adanya relaksasi otot pada bagian bawah perut dan nyeri berkurang dari yang sebelumnya dirasakan

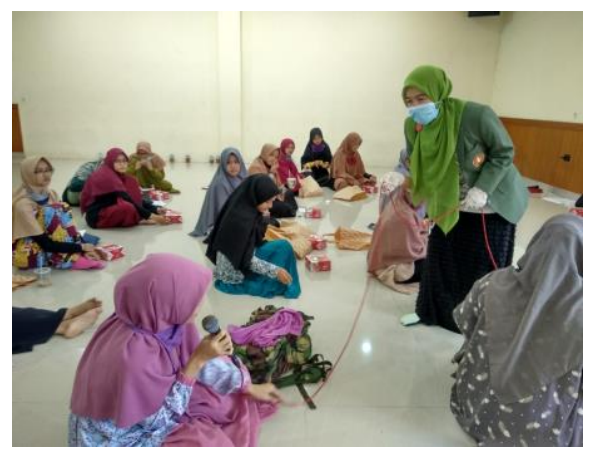



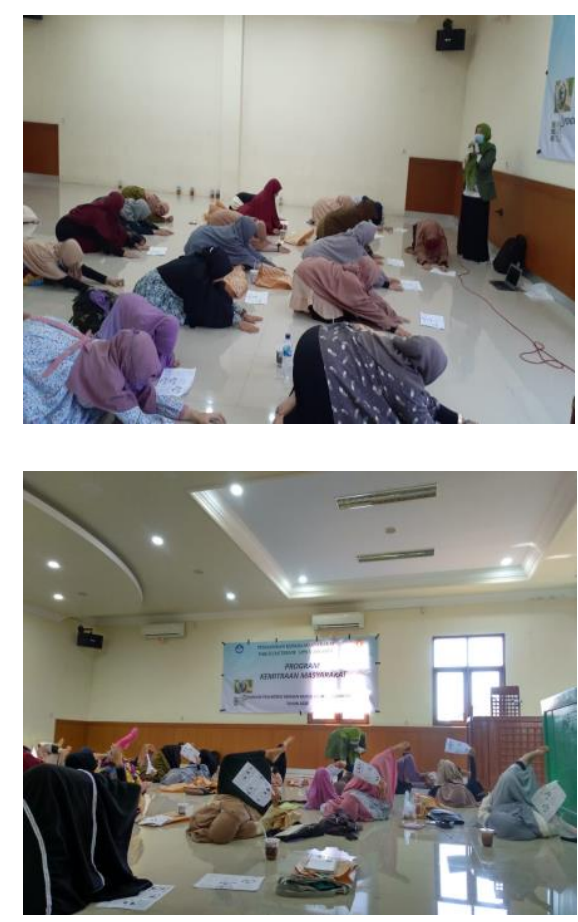

Gambar 1,2,3. Latihan abdominal stretching

\section{KESIMPULAN DAN SARAN}

\section{Kesimpulan}

Diperoleh dari 26 santriwati yang melakukan abdominal stretching bisa menurunkan intensitas nyeri haid pada remaja puteri di pesantern $\mathrm{Al}$ Musawwa, maka dapat disimpulkan bahwa latihan abdominal strteching dapat menurunkan intensitas nyeri haid karena adanya peran biologis tubuh dalam mengurangi rasa nyeri tersebut.

\section{Saran}

Berdasarkan hasil pengabdian direkomendasikan bagi remaja puteri dapat memberikan informasi serta menambah pengetahuan remaja dalam menangani nyeri haid (dismenorea) secara non-farmakologi dan aman yaitu dengan latihan abdominal stretching.

\section{DAFTAR PUSTAKA}

Batubara, Jose R.L. 2017. "Adolescent Development (Perkembangan Remaja)." Sari Pediatri.

Chan, Z.R., Desmawati. 2019. "Effect of abdominal stretching of menstrual pain (dysmenorrhea) in adolescent at junior high school 1 Depok". Prosiding. First International Conference on Health Development. ISBN 978-623-92728-0-7 hal 11

Gebeyehu, Minaleshewa B et al. 2017. "Prevalence, Impact, and Management Practice of Dysmenorrhea among University of Gondar Students, Northwestern Ethiopia: A Cross-Sectional Study." International Journal of Reproductive Medicine.

Kemalaningtyas, Rizqiana. 2016.

"Pengaruh Stretching dan

Strengthening Core Muscle Terhadap Penurunan Dismenorhea Premer." Universitas Muhammadiyah Surakarta.

Kevin C, Damajanty H.C Pangemanan, Joice N A, Engka. 2017. "Hubungan Antara Stres Dan Pola Siklus Menstruasi Pada Mahasiswa Kepaniteraan Klinik Madya (CoAssistant)." Jurnal e-Biomedik (eBm). Marlinda, Rofli, D. 2013. "Pengaruh senam Dismenore Terhadap Penurunan Dismenore pada Remaja Putri di Desa Sidoharjo Kecamatan Pati." Jurnal Keperawatan Maternitas.

Ningsih, Dewi A, Eliyawati. 2018.

"Pengaruh Senam Abdominal Stretching Terhadap Efektifitas Penurunan Nyeri Dismenorhea Primer Pada Remaja Putri Di MA AlAmiriyyah Blokagung Tahun 2018."

J-HESTECH (Journal Of Health Educational Science And Technology).

Rahmawati, Nike. 2017. " Pengaruh Pemberian Abdominal Stretching Terhadap Tingkat Nyeri Haid Dismenore pada Siswi di SMP N 30 Semarang." STIKES Telogorejo Semarang.

Rustam, E. 2015. "Gambaran Pengetahuan Remaja Puteri Terhadap Nyeri Haid." Jurnal Kesehatan Andalas.

Sabilu, Yusuf, Andi F.F. 2017. "Analisis Faktor Yang Berhubungan Dengan 
Kejadian Disminorea Pada Remaja Putri Di Sma Negeri 8 Kendari Tahun 2016." Fakultas Kesehatan Masyarakat Universitas Halu Oleo.

Sastra, Lenni, Jasmarizal, Maya S. G. 2014. "Pengaruh Terapi Emotional Freedom Technique Terhadap Penurunan Skala Nyeri Dismenorea pada Remaja." Jurnal Ipteks Terapan.

Windastiwi, W., Wahyu P, Mundarti. 2017. "Pengaruh Abdominal Stretching Exercise Terhadap Intesitas Nyeri Dismenorea Abdominal Stretching." Jurnal Kebidanan. 